\title{
HQSAR Study of Microsomal Prostaglandin E2 Synthase (mPGES-1) Inhibitors
}

\author{
Amor A. San Juan, ${ }^{\dagger,}$ Seung Joo Cho, ${ }^{+, *}$ and Hoon Cho ${ }^{8, *}$ \\ "Biochemicals Research Center, Korea Institute of Science and Technology, Seoul 130-650, Korea. "E-mail. chosi@kist.re.kr \\ University of Science and Technology, Daejeon 305-330, Korea \\ ${ }^{8}$ College of Engineering, Chostm University, Gwangiu 501-759, Korea. "E-mail: hcho@chostm.ac.kr \\ Received May 15, 2006
}

\begin{abstract}
Microsomal prostaglandin $E_{2}$ synthase (mPGES-1) is an enzyme that is associated with inflammation, pain. fever and cancer. Hologram quantitative structure activity relationship (HQSAR) was conducted on the series of MK-886 compounds acting as MPGES-1 inhibitors. A training set with 24 compounds was used to establish the HQSAR model. The best model was chosen based on the cross-validated correlation coefficient $\left(q^{2}=0.884\right)$ and the correlation coefficient $\left(r^{2}=0.976\right)$. The model was utilized to predict the activity of the eight-test set of compounds giving the predictive $r^{2}$ value of 0.845 . The descriptors of the model are based on fragment distinction (atoms, bond and connectivity) and fragment size (2-5 atoms). The atomic contribution maps generated from HQSAR were useful in identifying the important structural features responsible for the inhibitory activity of MK-886 inhibitors. Based on the generated model, the presence of hydrophobic biphenyl group seems to enhance inhibition of mPGES- 1 that is in agreement with the previous experiments. In addition, it seems important for a halogen to be substituted to the biphenyl ring and for an acyl group to be attached to the indole moiety for enhanced activity.
\end{abstract}

Key Words : IIQS $\Lambda$ R, Drug design, Inflammation, mPGES-1

\section{Introduction}

The biosynthesis of prostanoids is regulated by three sequential enzymatic steps' such as phospholipase A2 enzymes, cyclooxygenase (COX) enzymes, and various lineage-specific temminal prostanoid synthases. Prostaglandin E synthase (PGES) is present in various forms that isomerize COX-derived PGH2 specifically to PGE2. Two of them are membrane-bound enzymes and have been designated as $\mathrm{mPGES}-1$ and $\mathrm{mPGES}-2$. The microsomal prostaglandin E2 synthase (mPGES-1) $)^{2}$ is the terminal isomerase in the PGE2 synthetic pathway that is involved in inflammatory response. ${ }^{3}$ Specifically targeting mPGES-1 enzyme should interfere almost exclusively with inflammationinduced PGE2, leaving not only the constitutive PGE2 synthesis unaffected, but also the synthesis of other COXderived prostanoids. Therefore, MPGES-1 inhibition should have more selective effects compared to inhibition of enzymes earlier in the pathway.

There is an increasing interest to develop an inhibitor that might be selective to PGE2 synthesis by inhibiting mPGES1 , in effect avoiding many of the side effects associated with presently available non-steroidal anti-inflammatory drugs (NSAIDs). Specific removal of PGE2 by inhibition of mPGES-1 may be used to provide the control of inflammatory reactions with fewer side effects in comparison with presently used NSAIDs. To date there are no known specific inhibitors of mPGES-1. A study showed that the $N-(2-$ cyclohexyloxy-4-nitrophenyl)-methanesulfonamide (NS398 ) inhibitor (selective cyclooxygenase-2 inhibitor) potently inhibits mPGES-1 activity with an IC $\mathrm{I}_{50}$ value of $20 \mu \mathrm{M}$ in vitro. ${ }^{+}$Recent research showed that the MK- 886 series of inhibitors have promising higher activity for the inducible mPGES-1 membrane protein with the lowest $\mathbf{I C}_{50}$ value of 3 $\mathrm{nM}^{5}{ }^{5}$ The molecular design of potent mPGES-1 inhibitor using MK-886 derivatives might lead the way to the discovery of new anti-inflammatory drugs with few side effects. Moreover, the study will provide additional knowledge in understanding the inhibitory activity of mPGES-1 membrane-bound protein.

Hologram Quantitative Structure Activity Relationship (HQSAR) study is useful to explore the individual atomic contributions to the biological activity. In particular, the atomic contribution maps derived from the HQSAR model were utilized to understand the vital features of the compound's structural fragment corresponding to the biological activity. ${ }^{5}$ HQSAR simply utilize information about the atom and bond types from the 2D molecular topology of the various compounds. The significant advantages of HQSAR technique in studying the quantitative structure-activity relationships of mPGES- 1 inhibitors include no requirement for 3D structure of the compounds, shorter computation time, simple reproducibility, convenience and the visual color codes of atomic contribution maps. In this study, HQSAR analysis was employed to MK-886 series of inhibitors reported by Riendeau et al. ${ }^{6}$

\section{Methods}

Data set. The compounds used for the HQSAR analysis include MK-886 derivatives obtained from a report published by Riendeau et al. ${ }^{6}$ The report consists of 32 compounds with $\mathrm{IC}_{50}$ values in the range of 0.003 to $10 \mu \mathrm{M}$ (see Table 1) by which both of the training and test set compounds were 
Table 1. The binding affinity of MK-886 derivatives (Riendeau et al. [6])

\begin{tabular}{|c|c|c|c|c|c|c|c|c|}
\hline & $\begin{array}{l}\text { substituted MK-8 } \\
\text { compounds 1-14 }\end{array}$ & & $\begin{array}{l}\text { substituted it } \\
\text { compounds }\end{array}$ & $\begin{array}{l}\text { es for } \\
9\end{array}$ & & $\begin{array}{l}\text { stitute } \\
\text { comp }\end{array}$ & $\begin{array}{l}\text { enyl indoles } \\
20-32\end{array}$ & \\
\hline Compound & $\mathrm{R}_{1}$ & $\mathrm{R}_{2}$ & $\mathrm{R}_{3}$ & $\mathrm{R}_{4}$ & $\mathrm{R}_{5}$ & $\mathrm{X}$ & $\mathrm{Y}$ & $\mathrm{IC}_{50}(\mathrm{uM})$ \\
\hline 1 & $\mathrm{ClI}_{2}(4-\mathrm{Cl}-\mathrm{Ph})$ & $\mathrm{CO}_{2} \mathrm{II}$ & $S^{\prime} \mid 3 u$ & & & & & 1.600 \\
\hline 2 & II & $\mathrm{CO}_{2} \mathrm{ll}$ & $S^{\prime} 13 u$ & & & & & 10 \\
\hline 3 & Me & $\mathrm{CO}_{2} \mathrm{H}$ & $S^{\prime} \mathrm{Bu}$ & & & & & 10 \\
\hline 4 & $\mathrm{CH}_{2}\left(\mathrm{CH}^{-} \mathrm{CH}_{2}\right)$ & $\mathrm{CO}_{2} \mathrm{H}$ & $S^{\prime} \mathrm{Bu}$ & & & & & 6.700 \\
\hline 5 & $\left(\mathrm{CH}_{2}\right)_{3} \mathrm{Ph}$ & $\mathrm{CO}_{2} \mathrm{H}$ & $S^{\prime} \mathrm{Bu}$ & & & & & 3.200 \\
\hline 6 & $\mathrm{CH}_{2}(4-\mathrm{Cl}-\mathrm{Ph})$ & $\mathrm{CO} M \mathrm{Mc}$ & $\mathrm{S}^{\prime} \mathrm{Bu}$ & & & & & 7.200 \\
\hline 7 & $\mathrm{CH}_{3}(4-\mathrm{Cl}-\mathrm{Ph})$ & $\mathrm{CONH}_{2}$ & $\mathrm{~S}^{\prime} \mathrm{Bu}$ & & & & & 10 \\
\hline 8 & $\mathrm{CH}_{3}(4-\mathrm{Cl}-\mathrm{Ph})$ & $\mathrm{CO}_{2} \mathrm{H}$ & $\mathrm{Ph}$ & & & & & 6.400 \\
\hline 9 & $\mathrm{CII}_{3}(4-\mathrm{Cl}-\mathrm{Ph})$ & $\mathrm{CO}_{2} \mathrm{II}$ & O $\mathrm{Ph}$ & & & & & 0.650 \\
\hline 10 & $\mathrm{CII}_{2}(4-\mathrm{Cl}-\mathrm{Ph})$ & $\mathrm{CO}_{2} \mathrm{II}$ & $\mathrm{Cl}_{2}\left(4-{ }^{\prime}(3 \mathrm{u}-\mathrm{Ph})\right.$ & & & & & 0.290 \\
\hline 11 & $\mathrm{CII}_{2}(4-\mathrm{Cl}-\mathrm{Ph})$ & $\mathrm{CO}_{2} \mathrm{Il}$ & $\mathrm{CO}(2-\mathrm{Mc}-\mathrm{Ph})$ & & & & & 0.900 \\
\hline 12 & $\mathrm{CII}_{2}(4-\mathrm{Cl}-\mathrm{Ph})$ & $\mathrm{CO}_{2} \mathrm{ll}$ & $\mathrm{COCll} 2 \mathrm{~S}^{\prime} \mathrm{Bu}$ & & & & & 0.260 \\
\hline 13 & $\mathrm{Cl}_{2}(4-\mathrm{Cl}-\mathrm{Ph})$ & $\mathrm{CO}_{2} \mathrm{ll}$ & $\mathrm{COCll}_{2}^{\prime} 13 \mathrm{u}$ & & & & & 0.250 \\
\hline 14 & $\mathrm{Cl}_{2}(4-\mathrm{Cl}-\mathrm{Ph})$ & $\mathrm{CO}_{2} \mathrm{II}$ & Me & & & & & 1.100 \\
\hline 15 & & & & $\mathrm{H}$ & ${ }^{\top} \operatorname{Pr}$ & & & 4.300 \\
\hline 16 & & & & $\mathrm{H}$ & $\mathrm{H}$ & & & 3.200 \\
\hline 17 & & & & $\mathrm{~F}$ & $\mathrm{H}$ & & & 2.600 \\
\hline 18 & & & & ${ }^{t} \mathrm{~B} u$ & $\mathrm{H}$ & & & 0.330 \\
\hline 19 & & & & $\mathrm{Ph}$ & $\mathrm{H}$ & & & 0.600 \\
\hline 20 & & & & & & $\mathrm{Ph}$ & $\mathrm{H}$ & 0.160 \\
\hline 21 & & & & & & $\mathrm{H}$ & $\mathrm{Ph}$ & 0.016 \\
\hline 22 & & & & & & Cl & $\mathrm{Ph}$ & 0.022 \\
\hline 23 & & & & & & $\Gamma$ & $\mathrm{Pl}$ & 0.007 \\
\hline 24 & & & & & & $\Gamma$ & 5-(1,3-pyrazinyl) & 0.032 \\
\hline 25 & & & & & & $\mathrm{~F}$ & 3-pyridinyl & 0.012 \\
\hline 26 & & & & & & $F$ & 2-MeO-Pln & 0.005 \\
\hline 27 & & & & & & $F$ & 2-Cl-Ph & 0.004 \\
\hline 28 & & & & & & $F$ & 2-F-Ph & 0.008 \\
\hline 29 & & & & & & $\mathrm{~F}$ & 2-MeCO-Ph & 0.006 \\
\hline 30 & & & & & & $\mathrm{~F}$ & 2-Me-['h & 0.003 \\
\hline 31 & & & & & & $\Gamma$ & 2-M心-Ph & 0.033 \\
\hline 32 & & & & & & $\Gamma$ & 2-Mc-Ph & 0.031 \\
\hline
\end{tabular}

chosen. The training set of compounds were used to derive the model whereas, the test set of compounds were used to determine the predictability of the model. From these 32 compounds, only 24 compounds were selected as training set and 8 compounds $(1,7,9,16,20,24,26$ and 31) were taken as test set. The $\mathrm{IC}_{s 0}$ values of the training set were converted into pIC $50\left(-\log C_{50}\right)$ and subsequently used as dependent variables in the HQSAR analysis. The most potent compound from the series which is 3-[1-(4-chlorobenzyl)-5-(2-fluoro-2'-methyl-biphenyl-4-yl)-1H-indol-2yl]-2,2-dimethyl-propionic acid (see Figure 1) shows that the biaryl rings ( $A$ and $B$ ) yields the remarkable potency of the compound based on in vitro biochemical assay."

Molecular modeling by HQSAR. Hologram QSAR (HQSAR) is a recently developed molecular modeling package. ${ }^{5}$ The basis of HQSAR is from the concept of unity hashed binary bit strings called fingerprint ${ }^{7}$ that employs structural fragment to predict the activity of a potent compound. Molecular 2D-fingerprints had been a very popular tool in analyzing chemical similarity. In HQSAR molecular fragment, the 2[)-fingerprint is employed in predicting the biological activity of compounds. Particularly, HQSAR uses molecular hologram as an extended 2D-fingerprint that encodes elaborate structural information including stereochemistry as well as branched and cyclic molecular fragments. $\operatorname{HQSAR}^{8}$ is a robust technicpue that is fast, reliable and does not require alignment of compounds.

Molecular modeling calculations by HQSAR were performed using SYBYL" program version 7.1 on Silicon graphics origin 300 workstation with IRIX 6.5 operating system. In HQSAR approach, the initial step undertaken was the generation of molecular holograms from the structure of 


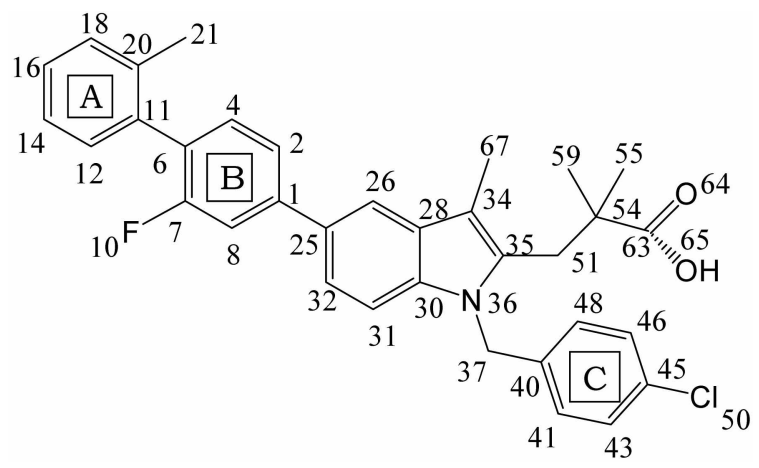

Figure 1. The two-dimensional chemical structure of the model compound.

compound, followed by correlation through statistical PI.S analysis. Molecular holograms were obtained by breaking down molecular structures into all possible linear and branched fragments of connected atoms. The 2T)-fingerprints of the compounds were generaled for all the substructures with topological descriptors based on fragment distinction (atoms, bond and connectivity) and fragment size (2-5 atoms). Fach unique fragment in a data set was then assigned a specific large positive integer by means of a cyclic redundancy check algorithm. Tach of these integers corresponds to a bin in an integer array of $53,59,61,71,97$, $151,199,275,307,353,401$, and 997 as fixed prime number hologram lengths. The computation of molecular holograms for a dalaset of structures generates data matrix with a dimension of $\mathrm{R} \times \mathrm{L}$. The $\mathrm{R}$ represents the number of compounds in the training set while $I$. represents the length of the molecular hologram. Subsecjuently, alter the molecular holograms were created, the statistical calculations were employed to finally generate a model inhibitor.

Statistical calculations. Partial least squares (PISS) methodology ${ }^{10.11}$ was employed to delermine the relationship between the 2D-fingerprint and biological activity of the compounds. To derive a HQSAR model, the structural features of the descriptors were used as independent variables and the $\mathrm{pIC}_{50}$ values were utilized as dependent variables in PLS analyses. Initially, the predictive value of the model was determined by leave-one-out (LOO) ${ }^{12}$ crossvalidation. The results from the LOO calculation were utilized to obtain the number of components that yield an optimally predictive model. Based on the generated model, the final calculation of the activity of compounds is represented by the mathematical equation below. The equation relates the values of molecular hologram bins to the corresponding biological activity in each of the compounds in the training set.

$$
\text { Aclivily }_{i}-\mathrm{c}_{\theta} \mid \sum_{t} \mathrm{c}_{i l} \mathrm{x}_{i l}
$$

The representations of the abbreviations in the equation are: Activity, represents the biological activity of the compound, $\mathrm{c}_{i}$ is a constant, $L$ is the hologram length, $c_{i r}$ is the coefficient for the bin derived from the PLS analysis, and $\mathrm{x}_{j /}$ is the occupancy value of the molecular hologram of compound $i$ at position or bin $l$.
HQSAR contribution maps. The graphical displays of the HQSAR computational analysis were shown by colorcoded structure diagram representing the degree of contribution of atoms in linearity with its activity. Poor atomic contributions were represented by the colors red, red-orange and orange that are located at the red end of the color spectrum. Favorable atomic contributions were represented by the colors yellow, green-blue and green that are localed at the green end of the color spectrum. On the other hand, intermediate atomic contributions were exhibited in color white. By default, HQSAR specilies the maximal common structure (MCS) based on the similar backbone present in all of the compounds from the training set. MCS is denoted by color cyan. It should be noted that the contribution to activity of the atoms involved in MCS were ignored since the template is common to all structures and thus, does not provide a distinguishing leature among the compounds in the dalaset.

Predictive $R$ squared $\left(r_{p r e d}^{2}\right)$. To validate the derived model from HQSAR, the biological activities of the eighttest set of compounds were predicted using the model generated from the training set. The predictive ability of the model is expressed by predictive $r^{2}$ value, which is similar to cross-validated $r^{2}\left(q^{2}\right)$ and is calculated by using the formula below:

$$
r_{\text {pret }}=\frac{\mathrm{SD}-\mathrm{PRTSS}}{\mathrm{SD}}
$$

wherein, SD is the sum of the squared deviation between the biological activities of the test set compounds and the mean activity of the training set compounds and PRT:SS is the sum of the squared deviations between the observed and the predicted activitics of the test set compounds.

\section{Results and Discussion}

A set of factors such as fragment size, number of fragments, atom types (A), bond types (B), atom hybridization or connectivity $(C)$, hydrogen bond and donor $(\mathrm{H})$, were modified to search the best cross-validation $r^{7}$ of the model. The fragment parameters including $A, B, C$ and $H$ were user-selectable flags that provided rules to determine the type of unique structural features of the model compound. Atom flag provides the ability to differentiate between fragments based on differences in element types. Bond flag distinguishes between fragments based on differences in bond types. Connection flag allows the distinction of hybridization state of the atoms in the fragment. Hydrogen flag distinguishes whether or not hydrogen atoms are included in the fragment.

In the initial HQSAR analysis, the default fragment size of 4-7 atoms was employed for the different combinations of fragment distinction (see Table 2) parameters including atom types (A), bond types, (B), connectivity (C), and hydrogen (H). Next, the best hologram length (L) and optimum number of components $(N)$ were selected based on the PLS analysis that gave the least cross-validated standard error 
Table 2. HQSAR analysis for various fragment distinction using fragment size (4-7)

\begin{tabular}{ccccccc}
\hline $\begin{array}{c}\text { Fragment } \\
\text { distinction }\end{array}$ & $\mathrm{q}^{2}$ & $\mathrm{SE}$ & $\mathrm{r}^{2}$ & $\mathrm{SE}$ & $\mathrm{N}$ & Length \\
\hline $\mathrm{A}$ & 0.783 & 0.576 & 0.894 & 0.403 & 3 & 353 \\
$\mathrm{~B}$ & 0.767 & 0.571 & 0.799 & 0.530 & 1 & 199 \\
$\mathrm{C}$ & 0.816 & 0.573 & 0.982 & 0.179 & 6 & 353 \\
$\mathrm{AB}$ & 0.795 & 0.547 & 0.860 & 0.452 & 2 & 257 \\
$\mathrm{AC}$ & 0.788 & 0.557 & 0.864 & 0.446 & 2 & 151 \\
$\mathrm{BC}$ & 0.861 & 0.472 & 0.983 & 0.165 & 4 & 353 \\
$\mathrm{ABC}$ & 0.870 & 0.457 & 0.986 & 0.149 & 4 & 307 \\
$\mathrm{AH}$ & 0.824 & 0.546 & 0.946 & 0.304 & 5 & 199 \\
$\mathrm{BH}$ & 0.739 & 0.617 & 0.798 & 0.543 & 2 & 353 \\
$\mathrm{CH}$ & 0.773 & 0.575 & 0.832 & 0.495 & 2 & 307 \\
$\mathrm{ABH}$ & 0.810 & 0.582 & 0.971 & 0.229 & 6 & 353 \\
$\mathrm{ACH}$ & 0.819 & 0.539 & 0.928 & 0.340 & 4 & 151 \\
$\mathrm{BCH}$ & 0.818 & 0.556 & 0.939 & 0.321 & 5 & 151 \\
$\mathrm{ABCH}$ & 0.847 & 0.523 & 0.968 & 0.240 & 6 & 151 \\
\hline
\end{tabular}

$\mathrm{q}^{2}$-LOO cross-validated correlation coefficient, SEcv --cross-validated standard ertor. $r^{2}$-noncross-validated cotrelation coeflicient, SE -noncross-validated standard etror. $\mathrm{N}$--number of components, Length hologram length, Fragmont distinction: A -aton types, B --bond types, $\mathrm{C} \rightarrow$ connectivity, II -hydrogen.

Table 3. HQSAR analysis for the influenec of various fragment sizes using the best fragment distinction $(N / \mathrm{B} / \mathrm{C})$

\begin{tabular}{ccccccc}
\hline $\begin{array}{c}\text { Fragment } \\
\text { size }\end{array}$ & $\mathfrak{q}^{2}$ & $\mathrm{SECV}$ & $\mathrm{r}^{2}$ & $\mathrm{SE}$ & $\mathrm{N}$ & Length \\
\hline $2-5$ & 0.884 & 0.431 & 0.976 & 0.196 & 4 & 97 \\
$3-6$ & 0.875 & 0.448 & 0.977 & 0.194 & 4 & 97 \\
$4-7$ & 0.870 & 0.457 & 0.986 & 0.149 & 4 & 307 \\
$5-8$ & 0.864 & 0.468 & 0.979 & 0.183 & 4 & 307 \\
$6-9$ & 0.867 & 0.474 & 0.982 & 0.173 & 5 & 151 \\
$7-10$ & 0.818 & 0.516 & 0.905 & 0.372 & 2 & 307 \\
\hline
\end{tabular}

$\mathrm{q}^{2}-$ LOO cross-validated correlation coefficient, SECv -cross-validated siandard etror. $r^{2}$-nonctoss-validated cotrelation coeflicient, SE -noncross-validated standard etror. $\mathrm{N}$--number of components, Length -hologram length.

(SEcv). The PLS analysis was repeated by employing different fragment sizes (see Table 3) using the best fragment distinction obtained from the previous step. Finally, a HQSAR model (hologram) was derived from the training set.

HQSAR model. A total of 24 structurally similar indoles served as training set to establish the model. The best HQSAR model was generated (descriptors: atoms, connections, bonds; fragment length: 2-5, hologram length: 97). The best model taken from the results of PLS analysis in the training set yielded (see Table 4 ) a cross-validated $q^{2}$ value of 0.884 with four optimal components, and non-cross validated $r^{2}$ value of 0.976 with a standard error of 0.431 . The selected model was validated by a test set of 8 compounds (shown as bold in Table 5), giving satisfactory predictive $r^{2}$ value of 0.845 . Based on the HQSAR model, the relationship between the experimental and predicted activities of both the training and test set were fairly
Table 4. Statistical indexes of HQSAR model

\begin{tabular}{ccccccc}
\hline Dataset & $\mathrm{q}^{2}$ & $\mathrm{SE} C \mathrm{Cr}$ & $\mathrm{r}^{2}$ & $\mathrm{SE}$ & $\mathrm{N}$ & Length \\
\hline Training & 0.884 & 0.431 & 0.976 & 0.196 & 4 & 97 \\
Test & 0.901 & 0.462 & 0.943 & 0.351 & 1 & 151 \\
\hline $\mathrm{q}^{2}$--LoO cross-validated correlation coeflicient, $\mathrm{SE} c \mathrm{r}$--cross-validated \\
standard error. $\mathrm{r}^{2}-$ noncross-validated correlation coefficient, SE - \\
noncross-validated standard error. N - number of components, Length \\
--hologram length.
\end{tabular}

Table 5. Relationship between experimental and predicted activities

\begin{tabular}{|c|c|c|c|}
\hline Compound & Experimental $\mathrm{p} / C 50$ & Predicted p $I C 50$ & Residual \\
\hline \multicolumn{4}{|l|}{ Training } \\
\hline 2 & -1.04 & -1.06 & -0.02 \\
\hline 3 & -1.04 & -0.96 & 0.08 \\
\hline 4 & -0.83 & -0.81 & 0.02 \\
\hline 5 & -0.51 & -0.61 & -0.10 \\
\hline 6 & -0.86 & -0.82 & 0.04 \\
\hline 8 & -0.81 & -0.76 & 0.05 \\
\hline 10 & 0.54 & 0.53 & -0.01 \\
\hline 11 & 0.05 & -0.09 & -0.14 \\
\hline 12 & 0.58 & 0.65 & 0.07 \\
\hline 13 & 0.60 & 0.69 & 0.09 \\
\hline 14 & -0.04 & -0.03 & 0.01 \\
\hline 15 & -0.04 & -0.03 & 0.01 \\
\hline 17 & -0.51 & -0.65 & -0.14 \\
\hline 18 & -0.41 & -0.39 & 0.02 \\
\hline 19 & 0.48 & 0.54 & 0.06 \\
\hline 21 & 0.80 & 1.30 & 0.50 \\
\hline 22 & 1.80 & 1.30 & -0.50 \\
\hline 23 & 1.66 & 1.79 & 0.13 \\
\hline 25 & 1.50 & 1.36 & -0.14 \\
\hline 27 & 2.30 & 2.07 & -0.23 \\
\hline 28 & 2.40 & 2.23 & -0.17 \\
\hline 29 & 2.10 & 2.14 & 0.04 \\
\hline 30 & 2.22 & 2.20 & -0.02 \\
\hline 32 & 1.48 & 1.68 & 0.20 \\
\hline \multicolumn{4}{|l|}{ Test } \\
\hline 1 & -0.20 & -0.57 & -0.37 \\
\hline 7 & -1.04 & -0.74 & 0.30 \\
\hline 9 & 0.19 & -0.16 & -0.35 \\
\hline 16 & -0.63 & 0.16 & 0.79 \\
\hline 20 & 0.22 & 0.28 & 0.06 \\
\hline 24 & 2.15 & 1.72 & -0.43 \\
\hline 26 & 1.92 & 1.55 & -0.37 \\
\hline 31 & 2.52 & 1.67 & -0.85 \\
\hline
\end{tabular}

predicted with residual values less than one log unit (see Table 5). In Figure 2, the graph represents the correlation between the experimental and predicted activities for both the training and test set of compounds.

Atomic contribution maps. The various colors of each atom reflect the degree of contribution towards the overall activity of the compound. The colors reflecting poor (or negative) contributions are at the red end of the spectrum (red, red orange, and orange), while the colors reflecting favorable (positive) contributions are at the green end (yellow, green blue, and blue). Atoms colored in white 


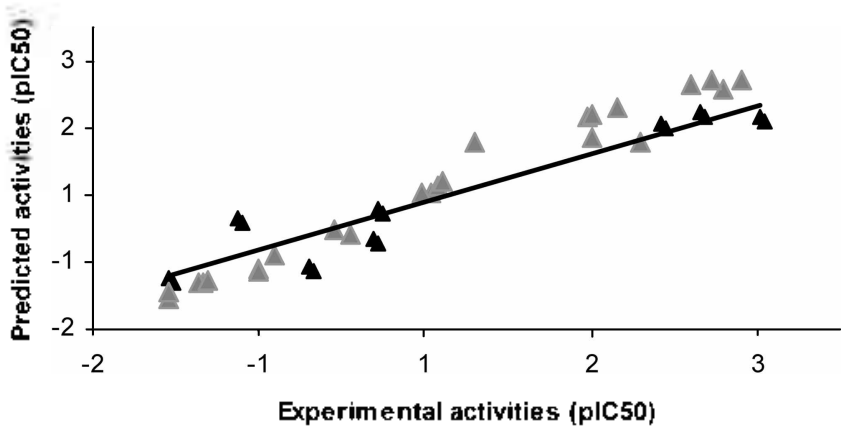

Figure 2. The plot of experimental and predicted activities $\left(r^{2}-\right.$ 0.9414 ) for series of MK- 886 inhibitors. The bold triangle denotes Iraining sel while the gray Iriangle represents test set.

reflect intermediate contributions.

In atomic contributions, the min_contrib and max_contrib denote the minimum and maximum PI.S coefficients related to the biological activity respectively, the colors used are:

\begin{tabular}{|c|c|c|}
\hline & red & $556 \mathrm{~min}$ contrib \\
\hline $5 / 6 \mathrm{~min}$ contrib & red orange & $<1 / 2 \min$ contrib \\
\hline $1 / 2 \min$ contrib< & orange & $<1 / 3 \min$ contrib \\
\hline $1 / 3 \mathrm{~min}$ contribe & white & $<1 / 3 \max$ conltrib \\
\hline $1 / 3 \max$ contribe & $y$ yellow & $12 m a x$ contrib \\
\hline $1 / 2 \max$ contrib $<$ & green bluc & $<5 / 6 m a x$ contrib \\
\hline 5/6max contrib & green & \\
\hline
\end{tabular}

For the system discussed in this work, the values of min_contrib and max_contrib were provided after the construction of HQSAR model and the colors reflect the contributions as below:

\begin{tabular}{|c|c|c|}
\hline & red & $<-0.0526825$ \\
\hline$-0.0526825<$ & red orange & $<-0.0316095$ \\
\hline$-0.0316095<$ & orange & $<-0.0210730$ \\
\hline$-0.0210730<$ & white & $<0.11352467$ \\
\hline $0.11352467<$ & ycllow & $<0.170287$ \\
\hline $0.170287<$ & green blue & $<0.2881167$ \\
\hline $0.2881167<$ & green & \\
\hline
\end{tabular}

Figure 3 depicts the individual atomic contribution of the model compound to its molecular bioactivity. It indicates that the hydrophobic biphenyl group mainly contributes the overall activity of the compound. The condensed rings $A$ and $\mathrm{B}$ (refer to Figure 1) were colored green and yellow (see Figure 3) which indicates positive contribution to the activity, suggesting that this is a pharmacologically important group. The particular atoms of the biphenyl ring with positive contributions to activity include $\mathrm{C}_{2}, \mathrm{C}_{4}, \mathrm{C}_{6}, \mathrm{C}_{7}, \mathrm{C}_{11}$, $\mathrm{C}_{12}, \mathrm{C}_{14}, \mathrm{Cl}_{50}$ and $\mathrm{F}_{1(1+}$ The importance of the hydrophobic group (biphenyl) attached to the indole ring is supported by the contribution map of other compounds (see Figures 4-5). In Figure 4, the contribution map marked a moderate activity

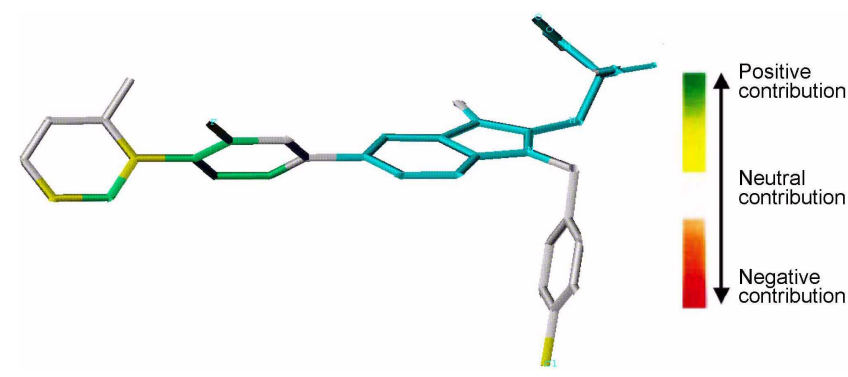

Figure 3. The atomic contribution map for the most potent inhibitor to mPGES-1. Green and yellow colors imply highest to higher atomic contributions to the activity, respectively. The atoms with inlermediale contributions are colored white while cyan color denotes the backbone structure.

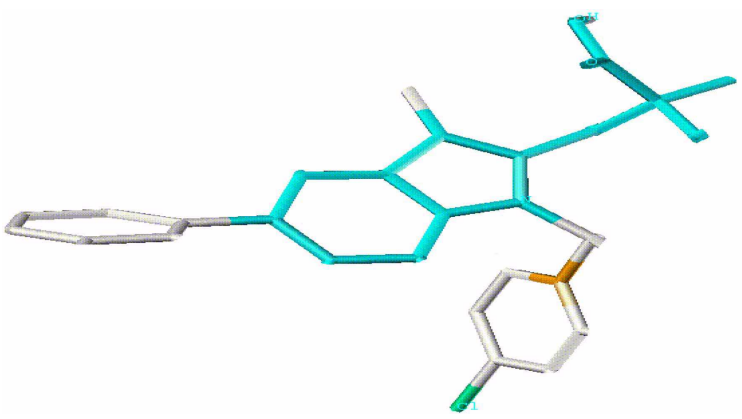

Figure 4. The intermediate contribution (white color) of the Bphenyl ring (refer to Figure I) 10 m['GES-] aclivily.

(white color) from a single phenyl group attached to the backbone structure indole (cyan). In Figure 5, the addition of another phenyl moicty to the existing benzene ring altached to the backbone indole indicated a high positive contribution to activity. When a 3-pyridinyl group was atlached into the A-phenyl group (see Figures 1 and 6), the color of the atomic contribution map has changed from green color (favorable activity) into white color (moderate aclivity). The addition of fluorine atom substituent to the B-phenyl ring (refer to Figure 1) suggested an enhance activity of the compound (see Figure 7). For further bioactivity improvement, the modification of atoms at $\mathrm{C}$ ring (refer to Figure 1) with color white (see Figure 3 ) might enhance activity. In Figure 8 , the presence of acyl substituent $\left(\mathrm{COCH}_{2} \mathrm{~S}^{\mathrm{B}} \mathrm{Bu}\right)$ yield favorable activity that implies this moiety should be maintained for future SAR studies.

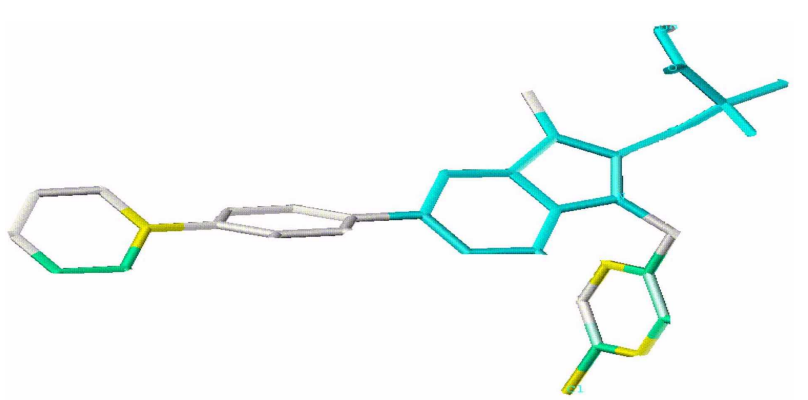

Figure 5. The enhancement to mPGES-1 activity by the presence of A-phenyl ring (refer to Figure 1). 


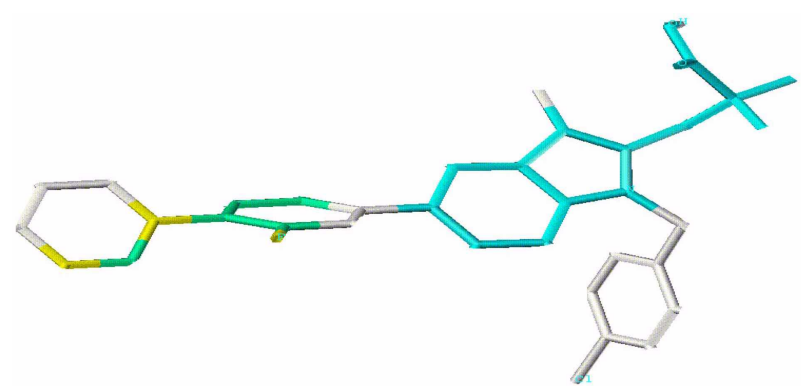

Figure 6. The intermediate activity of 3-pyridinyl attached to the B-phenyl ring (refer to Figure 1).

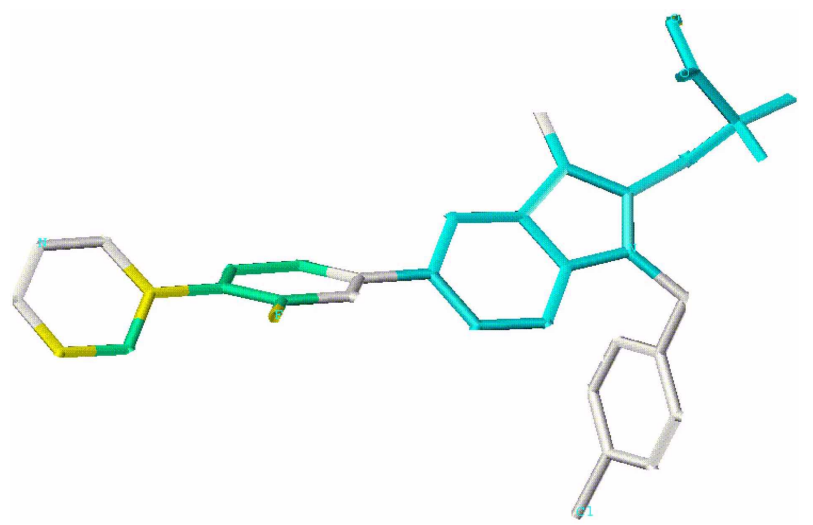

Figure 7. The positive contribution of electronegative fluorine atom attached to the B-phenyl ring (refer to Figure 1).

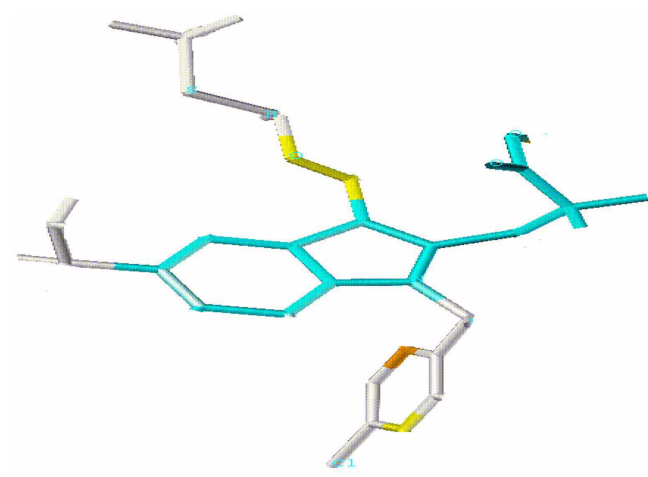

Figure 8. The positive contribution of acyl substituent (yellow color) to mPGES-1 activity.

Validation of the HQSAR model using test set. To verify predictability of the constructed HQSAR model based on the training set, 8 compounds were selected as testing set for validation. The predicted bioactivities of the test set were shown in Table 5. The correlation between the predicted and experimental results was depicted in Figure 2 (shown in bold triangles). The PLS analysis on the test set released crossvalidated $q^{2}$ value of 0.901 and $r^{2}$ value of 0.943 with a standard error of 0.462 . In addition, the predictive $r^{2}$ value of 0.845 may suggests a satisfactory model. All of the statistical results demonstrate that the HQSAR model is fairly reliable with good predictive ability and could be helpful in discovering new drugs for inflamunation.

\section{Conclusion}

The HQSAR study provides display of color codes to reflect which molecular fragments of the compound may be important contributors to the biological activity. The result indicates that the biphenyl ring and its substituent are the particular types of atoms that contribute to the overall activity of the model compound, in agreement with the previous experiment. ${ }^{6}$ The importance of hydrophobic biphenyl moicty with favorable aclivity is exemplified by further results of contribution maps. First, by attaching a monophenyl instead of biphenyl moicty to the core indole has indicaled an intermediate contribution to activity. Second, the altachment of 3-pyridinyl to A-phenyl moicty implied a lesser activity. On the other hand, the attachment of an acyl substituent to the 3-indolyl moicty of the model might enhance the activity. Based on the overall results, it seems reasonable to consider the relevance of the hydrophobic biphenyl group in mPGFS-1 aclivity. The hydrophobic group enhances mPGFS-1 inhibition that is in agreement with the report ${ }^{13}$ of fatty acid analogues as mPGES-1 inhibitors. In addition, the results suggest the halogen substitution to the biphenyl ring and the attachment of an acyl substituent to the indole moricty would favor activity to mPGT:S-1.

Acknowledgement. The study was supported by a research grant from Korea Research Foundation.

\section{References}

I. Kudo, I,; Murakami, M,; Prostaglandin, F. J. Biochem. Mol. Biol. $2005,38(6), 633-638$.

2. Shinji, Y.: Tsukui. T.: Tatsuguchi, M.; Shinoki, K.; Kusunoki, M.; Suzuki, K.: Hiratsuka, T,; Wada, K.: Futagami, S.; Miyake, K.: Gudis, K.; Sakamoto, C. Am. I. Phrsiol. Gastrointest Liver Phusiol 2005, 288, G308-G315.

3. Гk, M.; Tugblom, D.; Sala, S; Blomqvist, A; Jakobsson, P; Fricsson-Dah] strand, A. Neftute 2001, 410, 430-443.

4. Thoren, S.; Jakolssion, P. I. Ett. J. Biochem. 2000, 267, 64286434.

5. Lowis, D. R. Tripos Technical Notes $1997,1,1-16$.

6. Riendeau, D.; Aspiotis, R.; Ethier, D.; Gareau, Y.; Grimın, E.; Guay, J.: Guiral, S.: Juteau, Il.; Mancini, J.; Methot, N.; Rubin, 1.: Friesen, R. Bioorg. Med. Chem Leff. 2005, 15, 33523355 .

7. Hower, D. J. Chenn Inf. Comput. Sci. 1997, 38(3), 379386.

8. Cho, S. J. Budl. Korew Chem. Soc 2005, 26(1),85-90.

9. SYBY 7. 7), Tripos lnc.: St. I.ouis, 2004.

10. Cramer, R. D. Il]; Bunce, 1. D.; Patterson, D. F. Qutemt Strutet. Act. Refat. 1998. 7, 18-25.

11. Wold, S.; Albano, C.: Dunn, W.: Edlund, U.; Esbensen, K.; Geladi, I?; Hellberg, S.; Johansson, E.; Lindbery. W, Sjosstrom, M. In Chenomerrics: Mahematics and Statistics in Chemisty; Kowalski. B., T.d.; Reidel, Dordrecht. The Netherlands, 1987; PP 17-95.

12. Bush, B. L.: Nachbar, R. B. J. Comput Aided Mol. Des. 1993, 7, $587-619$.

13. Quraishi, O.; Mancini, J; Rindeau, D. Biochem. Pharmat 2002, $63,1183-1189$. 